\title{
Control of cellular senescence by CPEB
}

\author{
Irina Groisman, ${ }^{1}$ Maria Ivshina, ${ }^{1}$ Veronica Marin, ${ }^{1}$ Norman J. Kennedy, ${ }^{1}$ Roger J. Davis, ${ }^{1,2}$ \\ and Joel D. Richter ${ }^{1,3}$ \\ ${ }^{1}$ Program in Molecular Medicine, University of Massachusetts Medical School, Worcester, Massachusetts 01605, USA; \\ ${ }^{2}$ Howard Hughes Medical Institute, University of Massachusetts Medical School, Worcester, Massachusetts 01605, USA
}

\begin{abstract}
Cytoplasmic polyadenylation element-binding protein (CPEB) is a sequence-specific RNA-binding protein that promotes polyadenylation-induced translation. While a CPEB knockout (KO) mouse is sterile but overtly normal, embryo fibroblasts derived from this mouse (MEFs) do not enter senescence in culture as do wild-type MEFs, but instead are immortal. Exogenous CPEB restores senescence in the KO MEFs and also induces precocious senescence in wild-type MEFs. CPEB cannot stimulate senescence in MEFs lacking the tumor suppressors $\mathrm{p} 53, \mathrm{p} 19^{\mathrm{ARF}}$, or $\mathrm{p} 16^{\mathrm{INK} 4 \mathrm{~A}}$; however, the mRNAs encoding these proteins are unlikely targets of CPEB since their expression is the same in wild-type and KO MEFs. Conversely, Ras cannot induce senescence in MEFs lacking CPEB, suggesting that it may lie upstream of CPEB. One target of CPEB regulation is myc mRNA, whose unregulated translation in the KO MEFs may cause them to bypass senescence. Thus, CPEB appears to act as a translational repressor protein to control myc translation and resulting cellular senescence.
\end{abstract}

[Keywords: Senescence; CPEB; translational control]

Supplemental material is available at http://www.genesdev.org.

Received April 10, 2006; revised version accepted August 18, 2006.

Regulated mRNA translation plays an important role in early animal development and in the central nervous system. In oocytes, embryos, and neurons, several dormant mRNAs have short poly(A) tails; when the poly(A) tails are elongated in response to external stimuli, translation ensues (Wu et al. 1998; Groisman et al. 2002). The cytoplasmic polyadenylation element-binding protein (CPEB) is the key factor that controls this process; it binds the cytoplasmic polyadenylation element (CPE) in the $3^{\prime}$ untranslated regions (UTRs) of responding mRNAs. When phosphorylated on S174 or T171 (species-dependent), CPEB promotes polyadenylation by stimulating the activity of Gld-2 (Barnard et al. 2004), an atypical poly(A) polymerase (Kwak et al. 2004). The newly elongated tail then is bound by poly(A)-binding protein $(\mathrm{PABP})$, which promotes general translation by augmenting the assembly of the eIF4F initiation complex (Kahvejian et al. 2005). How the poly(A) tail and PABP stimulate translation of CPE-containing RNAs was revealed when a CPEB coimmunoprecipitating protein was identified. This protein, Maskin, binds not only $\mathrm{CPEB}$, but also the cap-binding factor eIF4E (StebbinsBoaz et al. 1999; Richter and Sonenberg 2005). The Maskin-eIF4E association competitively inhibits the

${ }^{3}$ Corresponding author.

E-MAIL joel.richter@umassmed.edu; FAX (508) 856-4289.

Article is online at http://www.genesdev.org/cgi/doi/10.1101/gad.1438906.
eIF4E-eIF4G association; thus, there is no eIF4G-assisted recruitment of the $40 \mathrm{~S}$ ribosomal subunit to the $5^{\prime}$ end of the mRNA. The poly(A) tail and PABP help eIF4G outcompete Maskin for binding to eIF4E, which results in eIF4F initiation complex assembly and translation /Cao and Richter 2002). Maskin phosphorylation also helps this protein dissociate from eIF4E (Barnard et al. 2005).

In early-stage embryos of Xenopus laevis, CPEB promotes polyadenylation-induced translation of cyclin B1 mRNA, which helps drive these atypical mitotic cell cycles that lack G1 and G2 phases (Groisman et al. 2002). Indeed, the injection of neutralizing CPEB antibody or dominant-negative mutant forms of this protein inhibits cell division (Groisman et al. 2000; Mendez et al. 2002). In contrast to these results in Xenopus, CPEB knockout $(\mathrm{KO})$ mice are viable and appear overtly normal, although they have defects in germ cell development (Tay and Richter 2001; Tay et al. 2003) and neuronal synaptic plasticity (Alarcon et al. 2004) and exhibit some behavioral anomalies (Berger-Sweeney et al. 2006). The observations that CPEB is essential for mitotic progression in Xenopus embryos and that mice lacking this gene display no phenotype that is obviously related to aberrant cell cycle progression might seem contradictory. However, some genes that are important for cell cycle progression in cultured cells have little effect in KO mice (Sherr and Roberts 2004; Malumbres and Barbacid 2005). To determine whether CPEB is important 
for cell cycle progression in mice, embryo fibroblasts (MEFs) from wild-type and CPEB KO animals were cultured according to a standard 3T3 protocol; there were no detectable differences in cell division. However, several passages after the initial cell cycle experiments were performed, the wild-type cells ceased to divide and entered a senescent stage, as expected (Sharpless et al. 2001). Amazingly, the KO MEFs did not senesce, but instead bypassed this process and were immortal up to at least 40 passages.

Senescence is a process that limits the number of times a cell divides in vitro; in mouse cells, it can be induced by DNA damage, the activation of certain oncogenes, or the stress of certain culture conditions (BenPorath and Weinberg, 2005). In vivo, senescence may be a tumor-suppression mechanism to prevent malignant transformation (Braig et al. 2005; Chen et al. 2005; Collado et al. 2005; Michaloglou et al. 2005) and contribute to organismal aging (Patil et al. 2005). While several genes influence senescence, perhaps the most central are the tumor suppressors p53, Rb, p19 ${ }^{\mathrm{ARF}}$, and $\mathrm{p} 16^{\mathrm{INK} 4 \mathrm{~A}}$. While $\mathrm{p} 19^{\mathrm{ARF}}$ and $\mathrm{p} 16^{\mathrm{INK} 4 \mathrm{~A}}$ are derived from the same locus, $\mathrm{p} 16^{\mathrm{INK} 4 \mathrm{~A}}$ is a cyclin-dependent kinase (CDK) inhibitor and thus an activator of $\mathrm{Rb}$, a transcriptional corepressor. p19 $\mathrm{ARF}$ activates the transcription activator p53 by antagonizing $\mathrm{Mdm} 2$, the ubiquitin ligase that mediates its destruction (Sherr 2004). Primary mouse cells that lack either of the abovementioned four tumor suppressors are immortal (Campisi 2003; Sherr 2004).

While exogenous CPEB restored senescence when expressed in CPEB KO MEFs and even induced precocious senescence in wild-type MEFs, it could not induce senescence in $\mathrm{p} 53, \mathrm{p} 19^{\mathrm{ARF}}$, or $\mathrm{p} 16^{\mathrm{INK} 4 \mathrm{~A}} / \mathrm{p} 19^{\mathrm{ARF}}$ double-KO MEFs. Conversely, activated Ras, which induces senescence in wild-type MEFs, could not do so in CPEB KO MEFs. The CPEB KO MEFs yielded a few small foci when grown in soft agar, suggesting that they may be partially transformed; however, they did not yield tumors when injected into athymic (nude) mice. p53, Rb, $\mathrm{p} 19^{\mathrm{ARF}}$, and $\mathrm{p} 16^{\mathrm{INK} 4 \mathrm{~A}}$ were all expressed in CPEB KO MEFs at levels similar to those observed in wild-type MEFs, although the $\mathrm{Rb}$ pocket proteins showed some changes. On the other hand, myc levels were aberrantly high in the KO MEFs, indicating that the mRNA encoding this protein might be misregulated in the KO MEFs. Indeed, myc RNA coimmunoprecipitates with CPEB from wild-type MEFs, and the CPE-containing myc 3' UTR, when appended to a reporter RNA, is responsible for elevated levels of translation in $\mathrm{KO}$ versus wild-type MEFs. Moreover, the elevated expression of myc in the wild-type MEFs may cause them to bypass senescence. These and other data suggest that CPEB-mediated downregulation of translation is necessary for mouse cells to become senescent.

\section{Results}

CPEB regulates cell senescence

To determine whether CPEB is important for the cell cycle, mouse embryo fibroblasts (MEFs) were prepared from embryonic day 14.5 (E14.5) embryos. At passage 2, the cells were cultured in medium lacking serum for 24 $\mathrm{h}$ and then cultured a subsequent $29 \mathrm{~h}$ in medium containing $10 \%$ serum. At several times, the cells were subjected to FACS analysis; both wild-type and KO MEFs recovered from quiescence induced by serum deprivation in an identical manner (Supplementary Fig. 1).

Wild-type and KO MEFs were further cultured according to a standard 3T3 protocol. A Western blot of the KO MEFs confirms that they do not express detectable levels of CPEB (Fig. 1A, left). Growth curves of four KO MEF lines show that they all bypassed senescence, while a wild-type line senesced after passage 6 (Fig. 1A, right). In other experiments, 14 of $17 \mathrm{KO}$ MEF lines were found to be immortal, while seven of seven wild-type lines became senescent (data not shown). Although only 12 passages are depicted in the figure, the KO MEFs have been cultured up to $\sim 40$ passages, demonstrating that they are immortal. A heterozygous MEF line also was immortal, indicating that the amount of CPEB is important for senescence (Fig. 1A). In other experiments, five of five additional heterozygous MEF lines also were immortal (data not shown).

To assess whether the KO MEFs were immortal because they lacked CPEB and not because of a mutation elsewhere in the genome, the KO MEFs were infected with a retrovirus expressing CPEB or, as a control, an empty virus. CPEB caused the KO MEFs to stop dividing, express senescence-associated $\beta$-galactosidase, and assume a flattened morphology typical of senescent cells (Ben-Porath and Weinberg 2005). Moreover, CPEB caused wild-type MEFs to undergo senescence prematurely (passage 4 instead of passage 7) and to express $\beta$-galactosidase (Fig. 1B; at right, a Western blot shows that similar amounts of heterologous CPEB were synthesized in wild-type and $\mathrm{KO} \mathrm{MEF}$ ). In other experiments, late (more than 25 ) passage KO MEFs or immortalized cells derived from wild-type MEFs infected with the same CPEB-expressing retrovirus elicited no discernible effect on cell division or morphology (data not shown). Therefore, this rescue experiment demonstrates that CPEB is essential for cell senescence and eliminates the possibility that the senescence bypass in the KO MEFs was caused by mutations in other genes.

To gain insight into other genes that might act in concert with $\mathrm{CPEB}$, we considered three that are known to be necessary for senescence: p53, p19 ${ }^{\mathrm{ARF}}$, and $\mathrm{p} 16^{\mathrm{INK} 4 \mathrm{~A}}$. We obtained MEFs that lack p53, p19 ${ }^{\mathrm{ARF}}$, or p19 $9^{\mathrm{ARF}}$ and

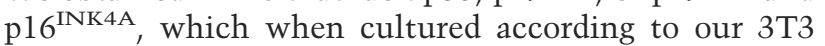
protocol, were, indeed, immortal (Fig. 1C). While CPEB induced the premature senescence of wild-type MEFs at passage 4 (as noted in Fig. 1B), it could not rescue senescence in MEFs that lack these three genes /cells infected at passage 4 and examined at passage 11). Thus, CPEB requires these tumor suppressors to induce senescence.

Finally, we determined whether oncogenic Ras, which induces premature senescence in mouse primary cells (Serrano et al. 1997), could also do so in cells that lack CPEB. CPEB KO and wild-type MEFs, as well as p19 19 ARF $\mathrm{KO}$ MEFs, were infected with a retrovirus expressing Ki- 

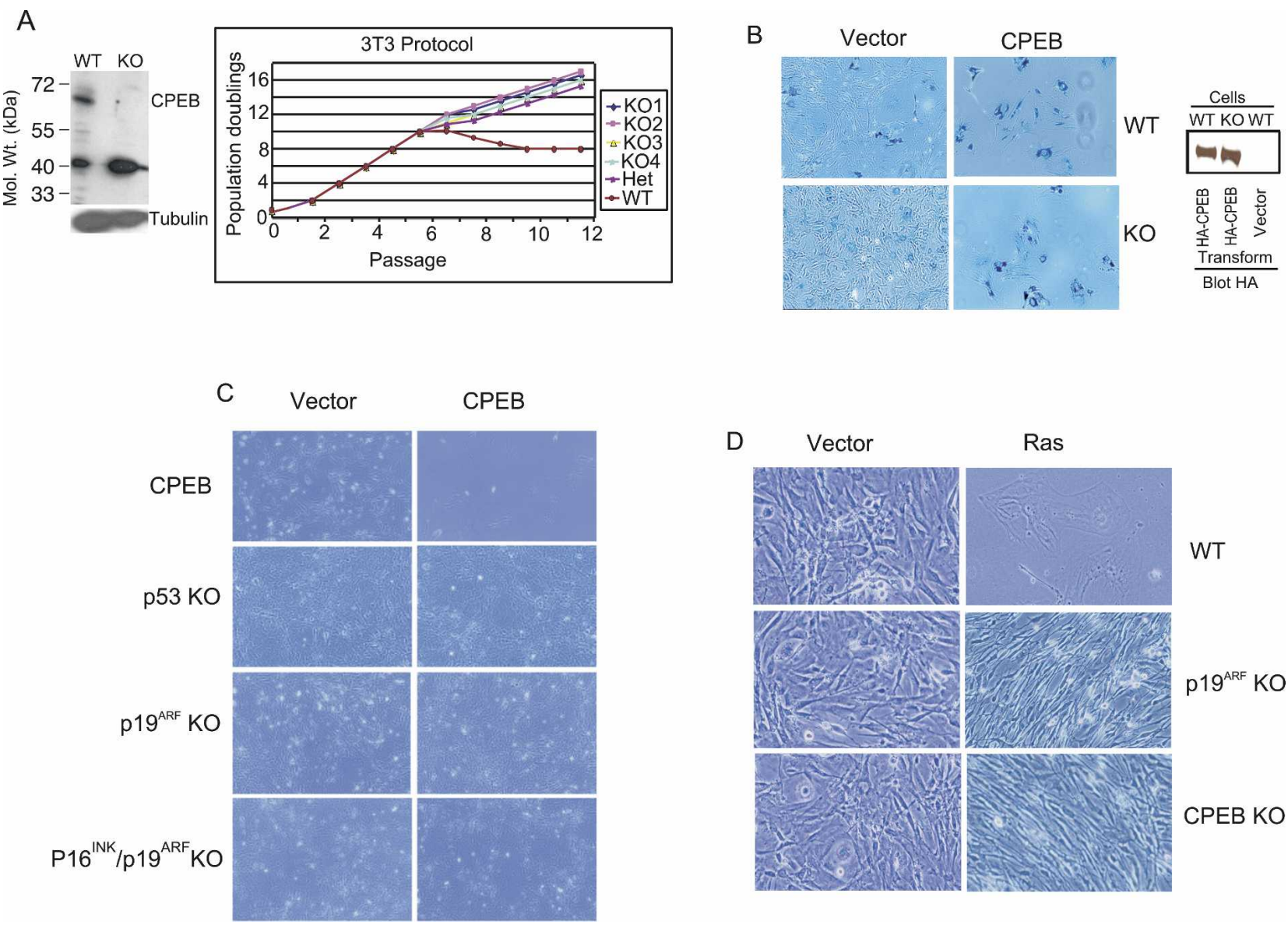

D

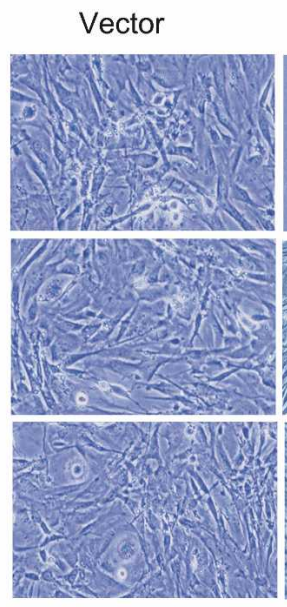

Ras

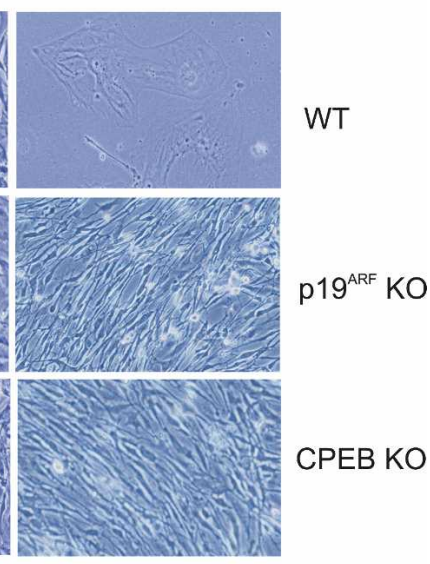

Figure 1. CPEB controls senescence in MEFs. $(A$, left) A Western blot of wild-type (WT) and CPEB KO MEFs probed for CPEB and tubulin. (Right) The rate of population doublings of four CPEB KO MEF lines and, for comparison, one wild-type line and one CPEB heterozygous line. The MEFs were cultured according to a 3T3 protocol. (B) Wild-type and CPEB KO MEFs were infected with a retrovirus expressing HA-tagged $\mathrm{CPEB}$, or an empty control vector, at passage 2 and then fixed at passage 4 (wild type) or passage 11 $(\mathrm{KO})$ and stained for $\beta$-galactosidase activity. Also shown is a Western blot demonstrating the expression of HA-tagged CPEB in wild-type and KO MEFs. (C) MEFs lacking CPEB, p19 $\mathrm{ARF}$, p16 $6^{\mathrm{INK}} / \mathrm{p} 19^{\mathrm{ARF}}$, or p53 were infected with the CPEB-encoding virus or an empty vector at passage 4 and examined by phase contrast microscopy at passage 11. (D) MEFs derived from wild-type, CPEB KO, and p19 ${ }^{\mathrm{ARF}} \mathrm{KO}$ animals were infected at passage 2 with a retrovirus expressing Ki-Ras or an empty vector, selected by puromycin at passage 3 , and examined by phase contrast microscopy at passage 5 .

Ras at passage 2, subjected to antibiotic selection at passage 3 , and examined at passage 5 . While this protein induced senescence of wild-type cells, it did not do so with the p19 $9^{\mathrm{ARF}}$ or CPEB KO MEFs (Fig. 1D). Thus, Rasinduced senescence cannot overcome the loss of these proteins.

\section{Transformation potential of CPEB KO MEFs}

The observation that CPEB KO MEFs are immortal suggests that they might display some features of a transformed phenotype. We examined four parameters to assess whether the KO MEFs might be at least partially transformed. First, transformed cells often display an elongated morphology; however, in contrast to immortalized cells derived from wild-type MEFs or early-passage wild-type and KO MEFs, late-passage KO MEFs had a distinctive round shape (Fig. 2A) that is not obviously related to partial transformation. Second, another assay to identify transformed cells is their ability to grow in medium containing reduced serum, typically $1 \%$. Under this culture condition, neither the KO nor the wild-type MEFs grew irrespective of whether they were infected with a Ras-bearing retrovirus (Fig. 2B). However, when the medium contained the normal $10 \%$ serum, the KO MEFs grew at a faster rate than immortalized cells derived from wild-type MEFs with or without exogenous Ras expression. These results suggest that the KO MEFs might have a tendency toward transformation. Third, we examined the ability of the KO MEFs to grow in soft agar, which is a widely used indicator of transformation. While immortalized cells derived from wild-type MEFs did not form any colonies in this medium, the KO MEFs did, although the colonies were small and not abundant (Fig. 2C). When transformed with Ras, the immortalized cells derived from wild-type MEFs and the KO MEFs 


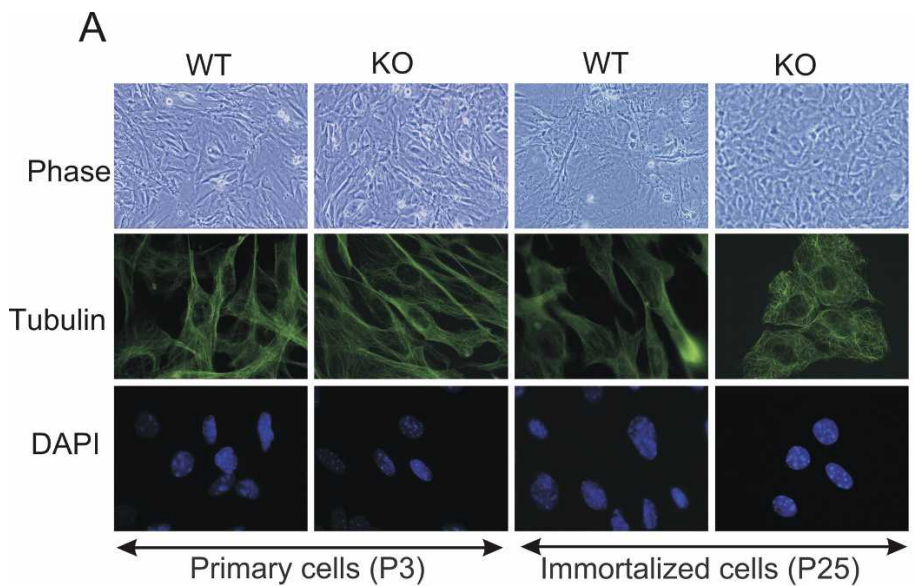

B

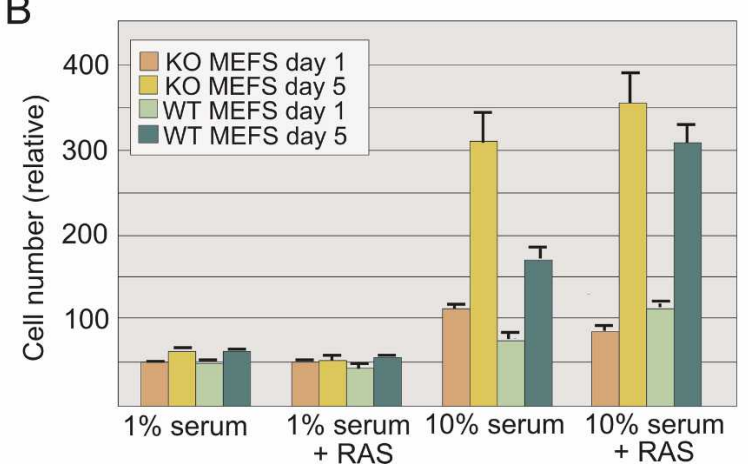

C
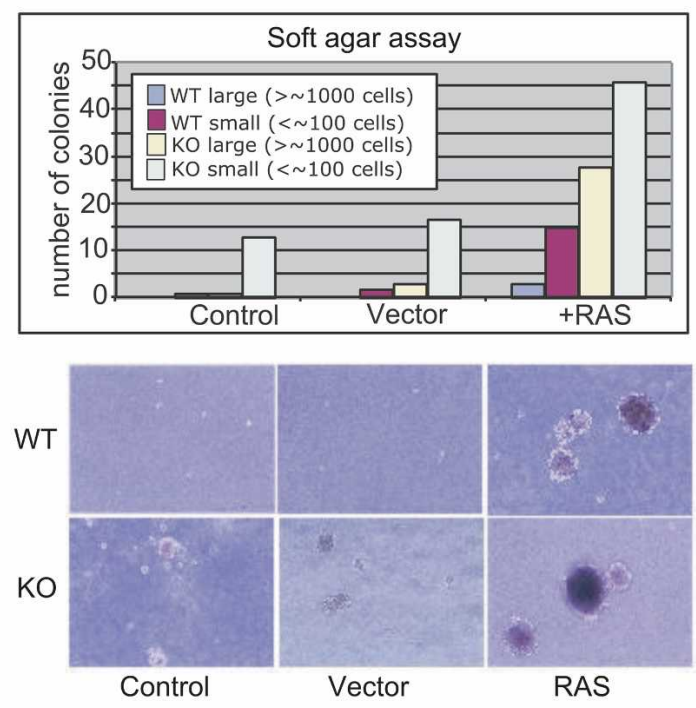

Figure 2. CPEB KO MEFs have features consistent with partial transformation. (A) Wild-type (WT) and CPEB KO MEFs were examined by phase contrast microscopy and immunostained for $\alpha$-tubulin at passages 3 and 25 (P3 and P25) to assess cell morphology. The cells were also stained with DAPI to visualize nuclei. (B) Wild-type and CPEB KO MEFs were cultured for up to $5 \mathrm{~d}$ in medium containing $1 \%$ or $10 \%$ serum and analyzed for cell number by staining with crystal violet (average $\pm S D, n=3$ ). Some of the MEFs were also infected with a retrovirus expressing Ki-Ras and were similarly examined. $(C)$ Wild-type and CPEB KO MEFs, some of which were infected with a Ki-Ras-containing virus or an empty virus vector as before, were grown on soft agar for 2 wk. Small foci were estimated to have $\sim 100$ cells, while large foci were estimated to have $\sim 500-1000$ cells.

both formed large and numerous colonies, although the latter were larger and more numerous. These data also suggest a tendency of KO MEFs toward transformation. Fourth, we determined whether late-passage (immortal) KO MEFs formed tumors in nude (athymic) mice. For comparison, immortalized cells derived from wild-type MEFs as well as both cell types transformed with Ras were also injected into nude mice. No tumors were observed in animals injected with immortalized $\mathrm{KO}$ or wild-type cells (data not shown), but as expected, tumors were evident in animals injected with cells (wild-type and $\mathrm{KO}$ ) that were transformed with Ras (Fig. 3A). Curiously, the 10 tumors derived from the KO MEFs all had large hematomas, while none of the 10 tumors derived from wild-type cells were so distinguished (Fig. 3A, arrows). Although the tumors appeared to grow at the same rate (Fig. 3B), the final weights (after $36 \mathrm{~d}$ of growth) of the wild-type tumors were usually greater than the KO tumors (Fig. $3 C)(p=0.01$, Student's $t$-test). Moreover, the morphologies of the tumors were different; the cells containing CPEB were densely packed and slightly elongated, while those lacking CPEB were larger, more irregularly shaped, and with nuclei usually displaced to the periphery (Fig. 3D). While the significance of these morphology differences remains to be elucidated, the aggregate data indicate that the CPEB KO MEFs are probably not transformed unless they are challenged with an oncogene.

\section{Altered levels of senescence-associated proteins in CPEB KO MEFs}

To examine whether key proteins that are thought to influence senescence are aberrantly expressed in the KO MEFs, a series of Western blots was performed (Fig. 4). The levels of $\mathrm{p} 53, \mathrm{p} 19^{\mathrm{ARF}}, \mathrm{p} 16^{\mathrm{INK}}$, and Rb (unphosphorylated and phosphorylated forms) were nearly the same in wild-type and KO MEFs, indicating that they are unlikely to be substrates of CPEB regulation. Note that the p53 antibody reacted with two proteins from wild-type and KO MEFs; to firmly identify p53, protein from p53 KO MEFs was also analyzed in parallel lanes, which demonstrated that the indicated band is, indeed, p53 and that it was present at similar levels in wild-type and KO MEFs. Myc as well as the $\mathrm{Rb}$ pocket proteins $\mathrm{p} 130$ and 107 were present at higher levels in the KO MEFs and all 
A
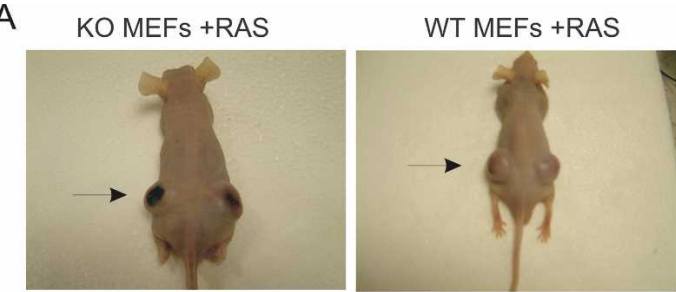

C

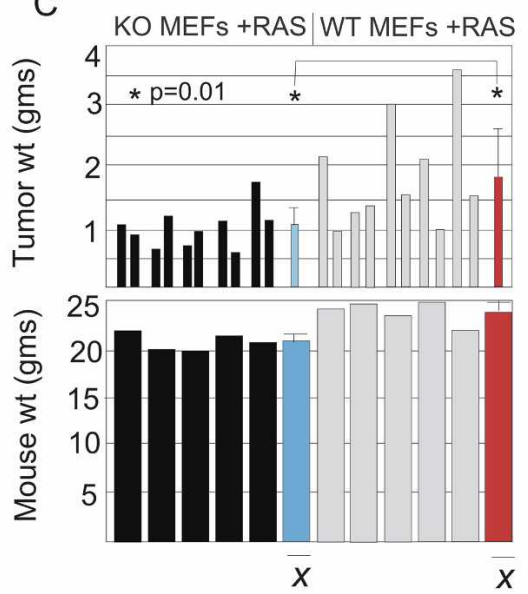

Tumor number (top) Mouse number (bottom)
B

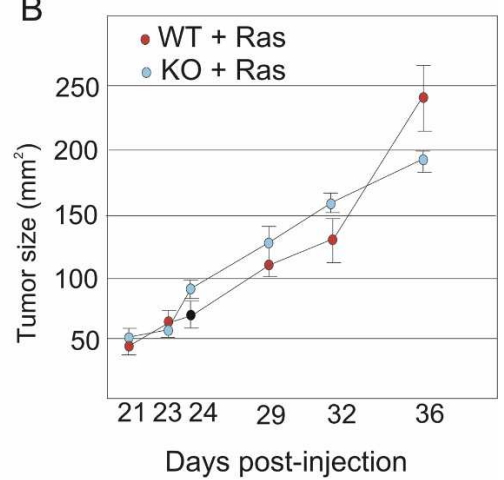

D

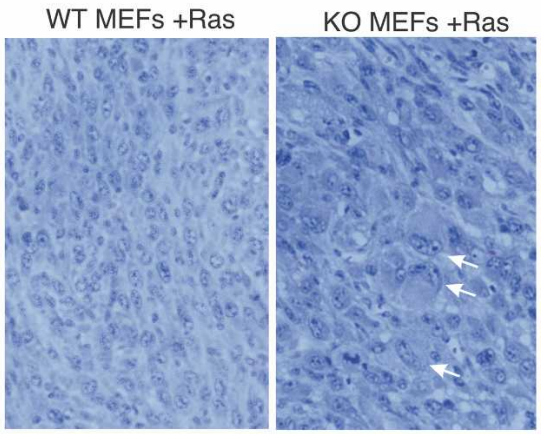

Figure 3. Tumors derived from wild-type (WT) and CPEB KO MEFs transformed with Ki-Ras. Immortalized cells derived from wild-type MEFs grown according to a 3T3 protocol as well as CPEB KO MEFs were infected with a retrovirus expressing Ki-Ras. The cells were injected subcutaneously into athymic (nude) mice (five mice each, two injections per mouse near each hind limb). All Ki-Ras-containing cells formed tumors irrespective of genotype (10/10 WT, 10/10 CPEB KO). (A) Representative pictures of the tumors at the sixth week after injection; note the hematoma on the tumors derived from the CPEB KO MEFs (cf. those denoted by arrows). All 10 tumors derived from the Ras-transformed KO cells had hematomas. (B) Tumor growth. (C) Final tumor and mouse weight 6 wk after injection. $(D)$ The tumors shown in $A$ were excised, sectioned, and stained with hematoxylin and eosin. Representative sections are shown. The arrows denote cells with enlarged cytoplasms and displaced nuclei.

have putative CPEs (Fig. 4), suggesting that aberrant translation of one or more of them in the KO MEFs might be responsible for senescence bypass.

The overexpression, not underexpression, of these proteins in the KO MEFs was a surprising finding. For example, the ablation of CPEB activity in Xenopus oocytes or embryos prevents translation (Groisman et al. 2000; Mendez et al. 2002) as does the removal of CPEB from oocytes of KO mice (Tay and Richter 2001). Thus, in these cases, CPEB is an activator of translation. Moreover, CPEB-stimulated translation requires phosphorylation of S174 or T171 (Xenopus and mouse, respectively) (Mendez et al. 2000; Tay et al. 2003). To assess whether CPEB-controlled senescence requires RNA binding and/ or T171 phosphorylation, the KO MEFs were infected with retroviruses expressing wild-type and deletion mutant CPEB proteins. Figure 5 shows that while wild-type $\mathrm{CPEB}$ rescued senescence in KO MEFs, CPEB proteins lacking either the two RNA-binding domains or the zinc finger, all of which are necessary for RNA binding (Hake et al. 1998), failed to do so. Conversely, CPEB with a T171A mutation did rescue senescence (this construct also contained an S177A; while there is no evidence that this residue is phosphorylated, the motif in which this residue lies strongly resembles that surrounding T171 and thus could be a secondary phosphorylation site). Therefore, while RNA binding is necessary for CPEBmediated senescence, T171 phosphorylation is not. Because this modification is required for polyadenylation (at least in oocytes and probably neurons as well), it may be that in MEFs, CPEB-regulated translation might not require polyadenylation.

\section{CPEB inhibits myc RNA translation}

To identify possible mRNA substrates of CPEB in MEFs, we performed a series of ribonucleoprotein (RNP) coimmunoprecipitation experiments. MEFs were infected with viruses expressing HA-CPEB (HA antibody precipitation is more efficient than CPEB antibody precipitation), followed by immunoprecipitation, RNA extraction, and RT-PCR detection of RNAs selected on the basis of their expression in MEFs and whether they have putative CPEs (Fig. 6A). RNAs encoding the Rb pocket proteins p107 and p130 and myc were immunoprecipitated with HA-CPEB (Fig. 6A, lane 2, cf. lane 1, where 


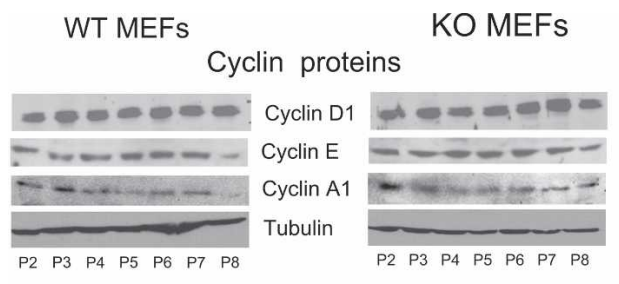

$\mathrm{Rb}$ family proteins

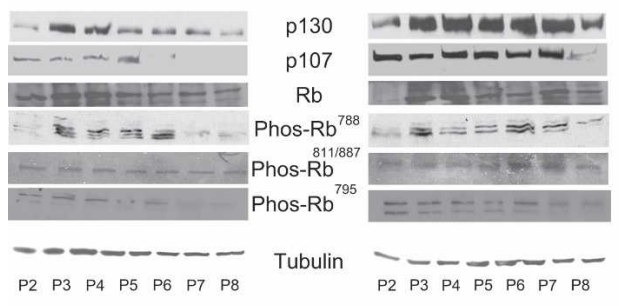

Senescence proteins

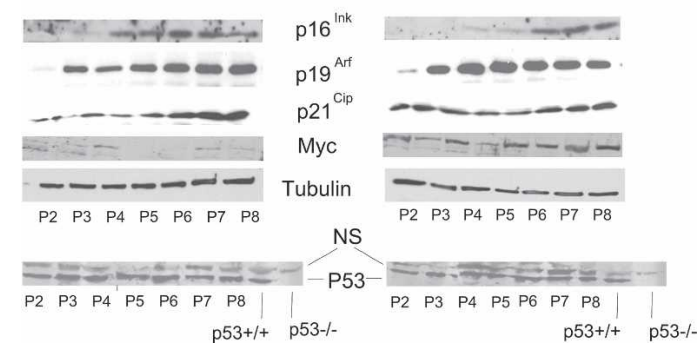

Figure 4. Expression levels of proteins involved in the cell cycle and cell senescence. Wild-type (WT) and CPEB KO MEFs were collected over passages 2-8 and examined by Western blotting for the indicated proteins. Tubulin served as the loading control and as a standard for film exposures among blots. Because the p53 antibody reacted strongly with two proteins from wild-type and CPEB KO MEFs, extracts from p53 KO and parallel wild-type MEFs were also analyzed. The faster migrating protein was absent from the p53 KO MEFs, demonstrating that it is p53. (NS) Nonspecific band.

HA was immunoprecipitated from uninfected cells.) RTPCR of a serial dilution of total RNA indicates the relative amount of the precipitated RNA (Fig. 6A, lanes 3-6). In addition, the RNA levels were the same in wild-type and KO MEFs and in KO MEFs infected with the CPEBcontaining virus (Fig. 6A, lanes 7-9). Controls in which the reverse transcription step was omitted did not yield amplification products (data not shown). These data show that some, but not all, CPE-containing RNAs can be immunoprecipitated with CPEB.

Because $\mathrm{Rb}$ protein levels were the same in wild-type and KO MEFs, the RNA encoding this protein is unlikely to be regulated by CPEB. On the other hand, the levels of p107, p130, and myc were all elevated in the KO MEFs (Fig. 4). Any of these proteins could contribute to senescence bypass; however, p107 and p130 have been knocked out in mice with no reported precocious MEF senescence (Sage et al. 2000), which would be expected if they were the direct downstream effectors of CPEB. (Note, however, that while oncogenic Ras induces senescence in $\mathrm{Rb} \mathrm{KO}$ MEFs, it cannot induce senescence in
$\mathrm{Rb} / \mathrm{p} 107$ or $\mathrm{Rb} / \mathrm{p} 107 / \mathrm{p} 130 \mathrm{KO}$ cells, thereby demonstrating the involvement of the pocket proteins in senescence [Sage et al. 2000; Pepper et al. 2001].) Because myc has been reported to be involved in senescence (Lutz et al. 2002) and because high levels of myc are detected in the CPEB KO MEFs that bypass senescence, we have focused our initial attention on this mRNA.

A UV cross-linking experiment was used to determine whether myc RNA is a direct target of CPEB. Recombinant CPEB was mixed with the myc 3' UTR that was synthesized in vitro in the presence of $\left[{ }^{32} \mathrm{P}\right] \mathrm{UTP}$. In some cases radioinert competitor RNA lacking or containing the CPE was also added to the mix, which was followed by UV irradiation, RNase digestion, and analysis by SDSPAGE and PhosphorImaging (Fig. 6B). CPEB was efficiently cross-linked to the RNA, which was reduced only when the competitor RNA contained a CPE. Thus, CPEB directly interacts with the myc 3' UTR CPEs.

Next, we repeated the CPEB-myc RNA coimmunoprecipitation experiment from MEFs as in Figure 6A, but in this case, excess competitor RNA lacking or containing the CPE was added to the extract prior to and during the immunoprecipitation procedure (Fig. 6C). The CPE-containing RNA effectively competed away the myc RNA from binding CPEB, while the CPE-lacking RNA had no effect. These data indicate that CPEB interacts with the myc 3' UTR CPEs in MEFs.

To confirm that the translation of myc RNA is regulated by $\mathrm{CPEB}$, as suggested by the data in Figure 4, ex-
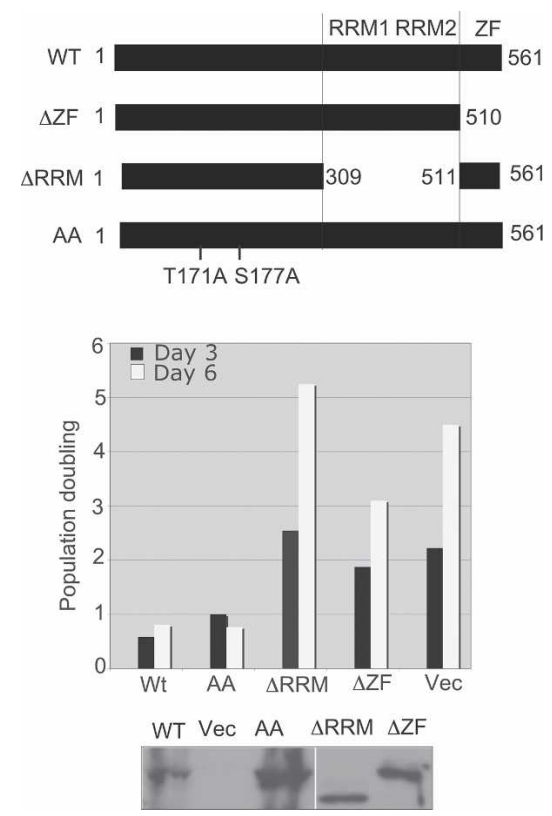

Figure 5. RNA binding but not phosphorylation is necessary for CPEB rescue of senescence. The CPEB KO MEFs were infected with virus expressing no CPEB (Vec), wild-type CPEB (WT), CPEB lacking the RRMs ( $\triangle R R M)$, CPEB lacking the zinc finger $(\triangle \mathrm{ZF})$, or CPEB with T171A/S177A mutations that prevent cytoplasmic polyadenylation. The cells were selected and counted on days 3 and 6 . The Western blot shows the relative levels of the virally expressed proteins. 


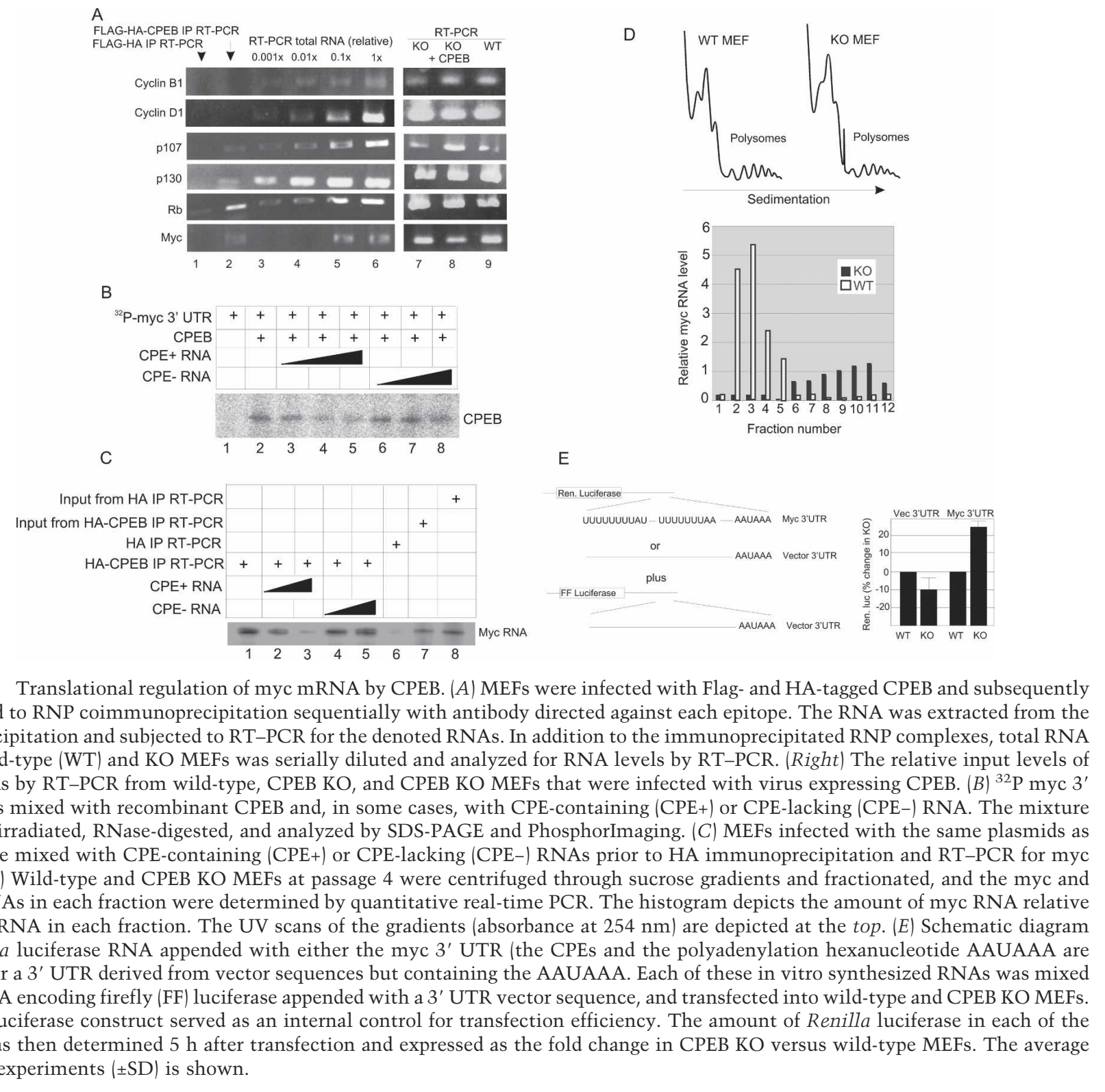

Figure 6. Translational regulation of myc mRNA by CPEB. (A) MEFs were infected with Flag-and HA-tagged CPEB and subsequently subjected to RNP coimmunoprecipitation sequentially with antibody directed against each epitope. The RNA was extracted from the final precipitation and subjected to RT-PCR for the denoted RNAs. In addition to the immunoprecipitated RNP complexes, total RNA from wild-type (WT) and KO MEFs was serially diluted and analyzed for RNA levels by RT-PCR. (Right) The relative input levels of the RNAs by RT-PCR from wild-type, CPEB KO, and CPEB KO MEFs that were infected with virus expressing CPEB. $(B)^{32} \mathrm{P}$ myc $3{ }^{\prime}$ UTR was mixed with recombinant CPEB and, in some cases, with CPE-containing (CPE+) or CPE-lacking (CPE-) RNA. The mixture was UV-irradiated, RNase-digested, and analyzed by SDS-PAGE and PhosphorImaging. $(C)$ MEFs infected with the same plasmids as in $A$ were mixed with CPE-containing (CPE+) or CPE-lacking (CPE-) RNAs prior to HA immunoprecipitation and RT-PCR for myc RNA. $(D)$ Wild-type and CPEB KO MEFs at passage 4 were centrifuged through sucrose gradients and fractionated, and the myc and actin RNAs in each fraction were determined by quantitative real-time PCR. The histogram depicts the amount of myc RNA relative to actin RNA in each fraction. The UV scans of the gradients (absorbance at $254 \mathrm{~nm}$ ) are depicted at the top. (E) Schematic diagram of Renilla luciferase RNA appended with either the myc 3' UTR (the CPEs and the polyadenylation hexanucleotide AAUAAA are shown) or a 3' UTR derived from vector sequences but containing the AAUAAA. Each of these in vitro synthesized RNAs was mixed with RNA encoding firefly (FF) luciferase appended with a 3' UTR vector sequence, and transfected into wild-type and CPEB KO MEFs. The FF luciferase construct served as an internal control for transfection efficiency. The amount of Renilla luciferase in each of the MEFs was then determined $5 \mathrm{~h}$ after transfection and expressed as the fold change in CPEB KO versus wild-type MEFs. The average of three experiments $( \pm S D)$ is shown.

tracts from wild-type and KO MEFs were centrifuged through sucrose gradients to resolve the polysomes and the nontranslating RNPs, which generally sediment less than 80 . The RNA was extracted from each fraction and subjected to real-time quantitative RT-PCR for actin and myc RNAs. When compared with actin RNA (whose sedimentation did not change in the wild-type vs. KO MEFs) (data not shown), the results in Figure 6D show that in wild-type MEFs, a substantial portion of myc RNA was not translated, but that much of this material was recruited into polysomes in the KO MEFs. Thus, CPEB appears to repress the translation of myc RNA.

Finally, a reporter Renilla luciferase RNA was appended with either this sequence or a control vector sequence; plasmid DNAs encoding these RNAs, together with one encoding firefly luciferase to serve as an internal standard, were transfected into wild-type and CPEB
KO MEFs followed by an analysis of luciferase activity. While both MEF types translated the RNA with the vector 3' UTR to about the same extent, the KO MEFs translated the RNA with the myc 3' UTR with greater efficiency than wild-type MEFs (Fig. 6E). Taken together, the results in Figure 6 demonstrate that CPEB inhibits myc mRNA translation.

\section{The regulated translation of Myc RNA by CPEB controls cell senescence}

Plasmid DNA encoding myc RNA with its own 3' UTR or one composed of vector sequence was transfected into wild-type and CPEB KO MEFs; DNA encoding vector sequence was also transfected. While none of the RNAs had an effect on growth of the CPEB KO MEFs, myc RNA with the vector 3' UTR caused the wild-type cells 
to bypass senescence when compared with the RNA encoding myc with its own 3' UTR or the noncoding RNA (Fig. 7A). Moreover, a Western analysis for Myc shows that the levels of this protein were high in wild-type MEFs transfected with myc RNA with the vector $3^{\prime}$ UTR, but lower in wild-type MEFs transfected with the other RNAs; Myc was also high in KO MEFs under all conditions (Fig. 7A). These results, together with those showing that similar amounts of heterologous myc RNA were present in the transfected cells (Fig. 7A; the lower panel depicts quantitative real-time PCR for the myc 3' UTR), suggest that CPEB represses the translation of myc RNA when it has its own CPE-containing 3' UTR, and that the levels of myc are important for regulating cell senescence.

These results imply that reduced myc levels in KO MEFs would induce senescence. To assess this possibility, a short hairpin RNA (shRNA) was used to knock down myc RNA; shRNA for GFP served as a control.
Figure 7B (top) shows that relative to the control shRNA the myc shRNA knocked down myc to $>95 \%$. A growth curve demonstrates that with reduced myc levels, the cells ceased to divide (Fig. 7B, middle panel; the cells are shown in the bottom panel).

Finally, we also assessed possible apoptosis in MEFs overexpressing myc. Although p19 ${ }^{\mathrm{ARF}}$ and p53 levels were somewhat elevated in these cells, we detected no significant apoptosis as assessed by TUNEL labeling or Western blotting for several apoptotic markers such as caspase 3, BAX, or BCL-2 (Supplementary Fig. 2). These data indicate that CPEB-mediated senescence occurs via translational control of myc RNA.

\section{Discussion}

This report demonstrates the necessity of CPEB for cellular senescence in MEFs. CPEB requires p53, p19 ${ }^{\mathrm{ARF}}$, and $\mathrm{p} 16^{\mathrm{INK} 4 \mathrm{~A}}$ to induce senescence; conversely, acti-
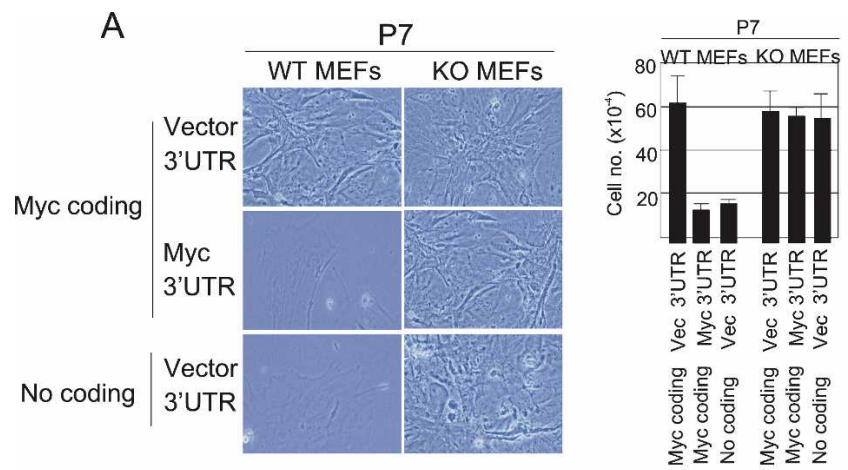

B
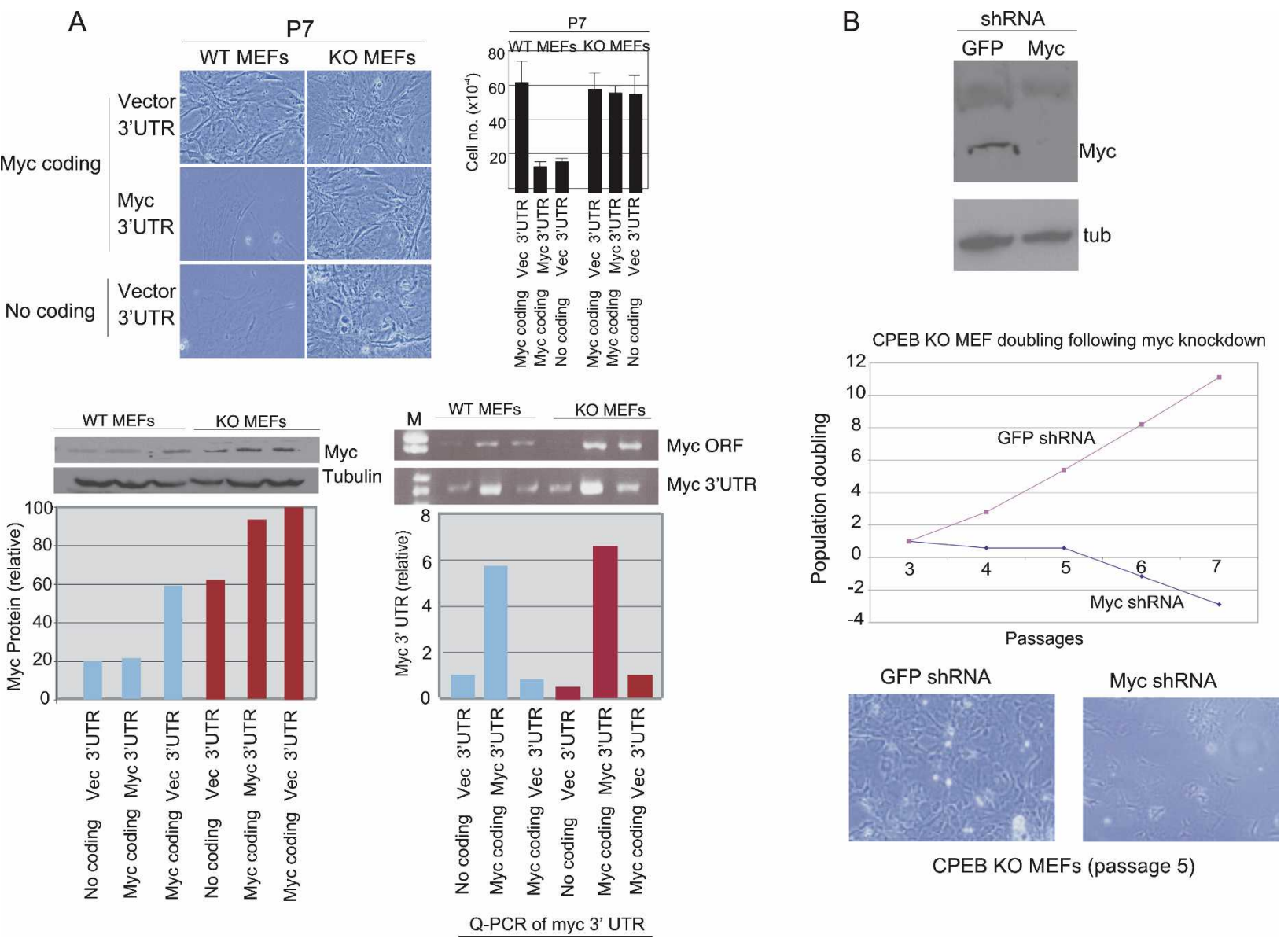

Figure 7. Myc RNA translation by CPEB controls senescence. (A) At passage 2, wild-type (WT) and CPEB KO MEFs were transfected with a retrovirus expressing the myc-coding region appended with its own 3' UTR or a 3' UTR derived from vector sequences. Some MEFs were infected with a virus containing only the vector. At passage 7, cell number was assessed by microscopy and by counting with a hemocytometer. Some of the cells were also used for Western blotting for myc and tubulin, and for RT-PCR of the myc ORF and 3' UTR. In addition, the myc 3' UTR was quantified by real-time PCR (histogram). The levels of this RNA were made relative to actin RNA, which was also quantified by real-time PCR. (B, top panel) KO MEFs were infected with shRNAs for myc or GFP at passage 2 and puromycin-selected, and a Western analysis for myc protein was performed at passage 5 . The cells were also examined for population doubling (middle panel) and phase contrast microscopy (bottom panel). 
vated Ras requires CPEB to stimulate this process. The CPEB KO MEFs are not transformed, and while they, like immortalized cells derived from wild-type MEFs, are transformed by Ras, their responses to this oncogene are not identical. That is, Ras causes the KO MEFs to form more and larger foci in soft agar compared with wild-type MEFs, and induces distinct shape changes in the $\mathrm{KO}$ MEFs in tumors formed in nude mice. While the significance of these results remains to be elucidated, they do indicate that immortalized wild-type and CPEB KO MEFs are not identical. Indeed, p53, whose disruption is usually associated with immortalization, is expressed at normal levels in the KO MEFs. Finally, CPEB interacts with several CPE-containing mRNAs whose encoded products are present at aberrantly high levels in the $\mathrm{KO}$ MEFs (p130, p107, myc) and the translation of one of them, myc, appears to regulate senescence.

The observation that CPEB is essential for cellular senescence is surprising. Several other proteins have been implicated in this process including eIF4E (Ruggero et al. 2004), a general factor that regulates all cap-dependent translation. Thus, the number of mRNAs whose translation could be affected by eIF4E overexpression is extremely large. CPEB, on the other hand, interacts only with CPE-containing RNAs, thus vastly restricting the potential mRNA substrates on which it could act to induce senescence. Even so, the identification of myc RNA as one substrate involved in this process was unexpected because its translation is reported to be under internal ribosome entry site (IRES) control, while CPEB mediates translation through eIF4E (see introduction and below). On the other hand, myc has long been known to regulate cell proliferation; it is low in nondividing cells and high in rapidly dividing cells (Campisi et al. 1984). Its overexpression can enhance the cell cycle, especially by shortening G1 (Karn et al. 1989), but can induce apoptosis as well (Thompson 1998). MEFs and other cells lacking myc have a reduced rate of proliferation (Mateyak et al. 1999). Our results show that a two- to threefold elevation in myc levels caused by the aberrant translation of its mRNA when the CPEs are deleted can lead to senescence bypass. Conversely, we show that a knockdown of myc causes MEFs to stop dividing.

We also examined the effects of myc overexpression on apoptosis in MEFs. In wild-type and KO MEFs, overexpressed myc induced a mild up-regulation of p53 and p19 ${ }^{\mathrm{ARF}}$, but we could detect no evidence of apoptosis (Supplementary Fig. 1). It is known that myc overexpression can induce apoptosis, as noted above, but in our case, myc may not have been at a sufficiently high level to induce apoptosis. Moreover, in the CPEB KO MEFs, perhaps other factors whose translation is controlled by $\mathrm{CPEB}$ are reduced or enhanced, which could offer some protection against apoptosis.

\section{Translational control by CPEB}

How CPEB might repress myc translation may be gleaned from its activity in other cells. In Xenopus oocytes, an RNP complex includes CPE-containing RNA,
CPEB, Maskin, and eIF4E, among other proteins. Through its association with CPEB, Maskin prevents translation of CPE-containing RNAs by preventing the interaction between eIF4E and eIF4G /Cao and Richter 2002). This repression is reversed when CPEB is phosphorylated by Aurora A on S174 (frog) or T171 (mouse) (Mendez et al. 2000; Tay et al. 2003). Because a T171A CPEB mutation rescues senescence, the phosphorylation of this residue, if it occurs in MEFs, cannot be necessary for the translational regulatory event by CPEB that mediates senescence. CPEB could still use Maskin-like molecules to repress translation. In this regard, a new $\mathrm{CPEB}$ and eIF4E-binding factor has been identified in Xenopus, mouse, and human cells. This protein, neuroguidin, represses translation in a CPE-dependent manner (Jung et al. 2006), and thus could mediate the activity of CPEB that is necessary for senescence.

CPEB also interacts with the RNA helicase p54 (Minshall et al. 2001). This protein inhibits translation by an unknown mechanism, but its activity may be related to its residence in p-bodies (Coller and Parker 2005). p-bodies, or processing bodies, were first shown to be centers for RNA destruction (Sheth and Parker 2003), but are now known to harbor translationally dormant mRNAs as well (Brengues et al. 2005). Recent evidence indicates that in HeLa cells, CPEB is present in p-bodies (Wilczynska et al. 2005). We have confirmed that in MEFs, $\mathrm{CPEB}$ is also present in p-bodies, among other regions in the cell (data not shown). While we do not know if myc RNA is also present in p-bodies, we speculate that it might be. Conversely, myc RNA might not be p-body associated in CPEB KO MEFs, thereby resulting in elevated levels of translation. It should also be noted that myc RNA contains an IRES (Stoneley et al. 1998), and thus its translation would require neither eIF4E nor eIF4G. However, myc RNA is also translated by capdependent translation, and the mode of translation it uses, cap versus IRES, is cell type dependent (Stoneley et al. 2000).

\section{Is CPEB a tumor suppressor?}

As determined by the absence of growth without serum, in soft agar, or in nude mice, the CPEB KO MEFs are not transformed. On the other hand, the KO MEFs transformed with Ras grow faster in medium containing serum, form larger foci in soft agar, and yield unusually shaped cells in nude mice compared with wild-type cells expressing Ras. These results suggest that MEFs lacking CPEB are slightly more susceptible to Ras-mediated transformation than CPEB-containing MEFs. If this is the case, then the CPEB KO mice might contract cancer at a higher rate than wild-type mice, especially if they express activated Ras or perhaps are exposed to a chemical mutagen. While neither wild-type nor CPEB KO animals aged nearly a year show signs of cancer (data not shown), experiments will be initiated to assess whether oncogenes or other carcinogens elicit an elevated rate of malignancy in the CPEB KO mice. 


\section{Materials and methods}

\section{Reagents}

Mouse CPEB (Gebauer and Richter 1996) was cloned into the XhoI-NotI sites of C-POZ, a retrovirus vector (Nakatani and Ogryzko 2003), or into the XhoI sites of pMSCVhyg (Clontech Laboratories, Inc.). The c-myc ORF, with or without its own 3' UTR (a gift from Michael Cole, Dartmouth Medical School, Hanover, NH), was cloned into the BamHI-EcoRI sites of pBabe, a retrovirus vector (Morgenstern and Land 1990). The myc 3' UTR was cloned into the XbaI-NotI sites of Renilla luciferase (pRL-TK; Promega).

Antibodies for cyclin E (C19), cyclin A (H432), cyclin D1 (DCS-6), Rb (IF8), p107 (C18), p130 (C20), and p21 (C19) were a gift from Andrew Koff (Memorial Sloan-Kettering, New York) and are designated according to Santa Cruz Biotechnology. Other antibodies were purchased from commercial suppliers (c-myc, sc 764, p16 ${ }^{\text {INK4A }}$, M-156 from Santa Cruz Biotechnology; p19 ${ }^{\mathrm{ARF}}$, ab80-100, Abcam; the hemagglutinin epitope, PRB101P, Covance; phospho-Rb, Ser 887/811, Ser 795, Ser 780, Cell Signaling; tubulin, Sigma).

\section{Cell culture and immunostaining}

Wild-type, $\mathrm{CPEB}^{+/-}$, and $\mathrm{CPEB}^{-/-} \mathrm{MEFs}$ were derived from E12.5-E14.5 embryos and cultured in Dulbecco's Modified Eagle's Medium with $10 \%$ fetal bovine serum using a 3T3 protocol. The cells were infected (Danos and Mulligan 1988) with retroviral vectors C-POZ mCPEB, pBabe-c-Myc-Puro, pMSCVmCPEB-Hyg, and pMSCV-Ki-Ras-Puro (gift from Valentina Evdokimova, University of British Columbia, Vancouver, BC, Canada), which were packaged using Bosch and Phoenix cells (Pear et al. 1993). To knock down myc, cells were infected with retrovirus pMSCV-puro into which the myc shRNA (or as a control, GFP shRNA) was cloned (Open Biosystems, clone SM2166 H-3). The infected cells were selected with $2 \mu \mathrm{g} / \mathrm{mL}$ puromycin or $400 \mu \mathrm{g} / \mathrm{mL}$ hygromycin, or by using magnetic beads containing antibody against the IL3 receptor, which is expressed on the surface of cells infected with C-POZ retrovirus vector (Nakatani and Ogryzko 2003). CPEB in pMSCV-Hyg was also introduced to $\mathrm{p} 19^{\mathrm{ARF}} \mathrm{KO}$, $\mathrm{p} 16^{\mathrm{INK} 4 \mathrm{~A}} / \mathrm{p} 19^{\mathrm{ARF}} \mathrm{KO}$ (gifts from Norman E. Sharpless, University of North Carolina, Chapel Hill, NC), and p53 KO (gift from Stephen Jones, University of Massachusetts Medical School, Worcester, MA) MEFs at passage 4 . Senescence-associated $\beta$-galactosidase activity was determined at pH 6.0 (Dimri et al. 1995). Soft agar assays were performed according to Clark et al. (1995).

To visualize the microtubules, wild-type and CPEB KO MEFs at passages 3 and 25 were immunostained with primary antibody against $\alpha$-tubulin and secondary antibody conjugated with green Alexa Fluor 488 (Molecular Probes). DNA was stained with DAPI. The coverslips were mounted with Prolong (Molecular Probes), and images were obtained with a Nikon Eclipse (E600) microscope at 100x.

The TUNEL reaction was performed using an In Situ Death Detection POD kit (Roche). DNase I-treated cells were used as a positive control.

\section{Biochemical assays}

Wild-type MEFs were infected with a retrovirus encoding Flagand HA-tagged CPEB. Cells obtained from $150 \mathrm{mM}$ plates were lysed in buffer containing $20 \mathrm{mM}$ Tris- $\mathrm{HCl}(\mathrm{pH} 8), 0.2 \mathrm{mM}$ EDTA, $0.1 \%$ Tween $20,0.1 \mathrm{M} \mathrm{KCl}, 10 \%$ glycerol, $10 \mathrm{mM}$ $\beta$-mercaptoethanol, and protease inhibitors and subsequently subjected to RNP coimmunoprecipitation sequentially with an- tibody directed against each epitope (Nakatani and Ogryzko 2003). The RNA was extracted from the final precipitate and subjected to an RT reaction with SuperScript II (Invitrogen) with an oligo(dT) primer.

Renilla luciferase was cloned into pRL-TK vector (Promega) mRNA and appended with either the myc 3' UTR (the myc 3' UTR sequence is found in Ensembl ENSMUST22971) or a 3' UTR derived from vector sequence; the RNA was synthesized in vitro with T7 RNA polymerase (mMassage mMachine kit; Ambion). Each of these RNAs was mixed with RNA encoding firefly luciferase appended with a $3^{\prime}$ UTR vector sequence and transfected into wild-type and CPEB KO MEFs with TransMessenger Transfection Reagent (Qiagen). The amount of Renilla luciferase in each of the MEFs was then determined $4 \mathrm{~h}$ after transfection with the Dual-Luciferase Reporter Assay System (Promega) and expressed as a fold change in CPEB KO versus wild-type MEFs.

Wild-type and CPEB KO MEFs were infected at passage 2 with pBabe-c-Myc-Puro (myc ORF with its own 3' UTR or one with a vector $3^{\prime}$ UTRone) or pBabe-Puro (vector alone). The levels of myc mRNA and protein were assessed by the RT-PCR reaction and Western blotting, respectively. Total RNA or protein was prepared from $100 \mathrm{mM}$ plates of MEFs cultured to passage 4 . One microgram of total RNA was used for RT-PCR or quantitative real-time one-step RT-PCR with the QuantiTect SYBR RE-PCR Qiagen kit. The relative fold changes were calculated using the $2^{-\Delta \Delta \mathrm{Ct}}$ method. Western blot analyses were performed on one-fourth of the material from cells grown on $100 \mathrm{mM}$ plates.

Polysome fractionation was performed according to Ruan et al. (1997). MEFs at passage 4 were obtained from three $10-\mathrm{cm}$ plates and were centrifuged through $15 \%-50 \%$ sucrose and fractionated, and the RNA from each fraction was extracted and used for oligo(dT)-primed quantitative real-time PCR for myc and actin RNAs. The amount of myc RNA was normalized to the amount of actin RNA in each fraction. Relative fold changes were calculated using the $2^{-\Delta \Delta \mathrm{Ct}}$ method.

For UV cross-linking (Hake and Richter 1994), [ $\left.{ }^{32} \mathrm{P}\right] \mathrm{UTP}-\mathrm{la}-$ beled myc 3' UTR (20 fmol) was mixed with recombinant CPEB (1 $\mu \mathrm{mol}$ ) plus $0,3,6$, and $30 \mathrm{pmol}$ of competitor RNA (cyclin B1 3' UTR containing or lacking the CPE) and irradiated with UV light. The RNA was then digested with RNase A and T1, and the products were resolved by SDS-PAGE and PhosphorImaging.

\section{Mice and histology}

Immortalized wild-type and CPEB KO MEFs, some of which were infected with a Ki-Ras-expressing retrovirus, were injected subcutaneously into 12-wk-old male athymic (nude) mice (Charles River) $\left(\sim 10^{6}\right.$ cells per injection, one injection near each hind limb of each of 10 mice). The mice were euthanized 6 wk post-injection, and the tumors were dissected, weighed, fixed, and processed for histological analysis. Paraffin-embedded sections were stained with hematoxylin and eosin.

\section{Acknowledgments}

We thank David Garlick, Nic Jones, Michelle Kelleher, and Jackie Lees for advice and Mike Cole, Valentina Evdokimova, Regina Groisman, Steve Jones, Andy Koff, Martine Roussel, and Norman Sharpless for reagents. V.M. was supported by an Institutional Post-doctoral Training Grant (HD07312). This work was supported by grants from the NIH (HD37267 and GM46779) and the G. Harold and Leila Y. Mathers Charitable 
Foundation. Additional core support from the Diabetes and Endocrinology Research Center Program Project (DK32520) is gratefully acknowledged.

\section{References}

Alarcon, J.M., Hodgman, R., Theis, M., Huang, Y.S., Kandel, E.R., and Richter, J.D. 2004. Selective modulation of some forms of schaffer collateral-CA1 synaptic plasticity in mice with a disruption of the CPEB-1 gene. Learn. Mem. 11: 318327.

Barnard, D.C., Ryan, K., Manley, J.L., and Richter, J.D. 2004. Symplekin and xGLD-2 are required for CPEB-mediated cytoplasmic polyadenylation. Cell 119: 641-651.

Barnard, D.C., Cao, Q., and Richter, J.D. 2005. Differential phosphorylation controls Maskin association with eukaryotic translation initiation factor $4 \mathrm{E}$ and localization on the mitotic apparatus. Mol. Cell. Biol. 25: 7605-7615.

Ben-Porath, I. and Weinberg, R.A. 2005. The signals and pathways activating cellular senescence. Int. J. Biochem. Cell Biol. 37: 961-976.

Berger-Sweeney, J., Zearfoss, N.R., and Richter, J.D. 2006. Reduced extinction of hippocampal-dependent memories in CPEB knockout mice. Learn. Mem. 13: 4-7.

Braig, M., Lee, S., Loddenkemper, C., Rudolph, C., Peters, A.H., Schlegelberger, B., Stein, H., Dorken, B., Jenuwein, T., and Schmitt, C.A. 2005. Oncogene-induced senescence as an initial barrier in lymphoma development. Nature 436: 660-665.

Brengues, M., Teixeira, D., and Parker, R. 2005. Movement of eukaryotic mRNAs between polysomes and cytoplasmic processing bodies. Science 310: 486-489.

Campisi, J. 2003. Cancer and ageing: Rival demons? Nat. Rev. Cancer 3: 339-349.

Campisi, J., Gray, H.E., Pardee, A.B., Dean, M., and Sonenshein, G.E. 1984. Cell cycle control of c-myc but not c-ras expression is lost following chemical transformation. Cell 36: 241247.

Cao, Q. and Richter, J.D. 2002. Dissolution of the maskin-eIF4E complex by cytoplasmic polyadenylation and poly(A)-binding protein controls cyclin B1 mRNA translation and oocyte maturation. EMBO J. 21: 3852-3862.

Chen, Z., Trotman, L.C., Shaffer, D., Lin, H.K., Dotan, Z.A., Niki, M., Koutcher, J.A., Scher, H.I., Ludwig, T., Gerald, W., et al. 2005. Crucial role of p53-dependent cellular senescence in suppression of Pten-deficient tumorigenesis. $\mathrm{Na}$ ture 436: 725-730.

Clark, G.J., Cox, A.D., Graham, S.M., and Der, C.J. 1995. Biological assays for Ras transformation. Methods Enzymol. 255: 395-412.

Collado, M., Gil, J., Efeyan, A., Guerra, C., Schuhmacher, A.J., Barradas, M., Benguria, A., Zaballos, A., Flores, J.M., Barbacid, M., et al. 2005. Tumour biology: Senescence in premalignant tumours. Nature 436: 642.

Coller, J. and Parker, R. 2005. General translational repression by activators of mRNA decapping. Cell 122: 875-886.

Danos, O. and Mulligan, R.C. 1988. Safe and efficient generation of recombinant retroviruses with amphotropic and ecotropic host ranges. Proc. Natl. Acad. Sci. 98: 6460-6464.

Dimri, G.P., Lee, X., Basile, G., Acosta, M., Scott, G., Roskelley, C., Medrano, E.E., Linskens, M., Rubelj, I., Pereira-Smith, O., et al. 1995. A biomarker that identifies senescent human cells in culture and in aging skin in vivo. Proc. Natl. Acad. Sci. 92: 9363-9367.

Gebauer, F. and Richter, J.D. 1996. Mouse cytoplasmic polyadenylylation element binding protein: An evolutionarily con- served protein that interacts with the cytoplasmic polyadenylylation elements of c-mos mRNA. Proc. Natl. Acad. Sci. 93: 14602-14607.

Groisman, I., Huang, Y.S., Mendez, R., Cao, Q., Theurkauf, W., and Richter, J.D. 2000. CPEB, maskin, and cyclin B1 mRNA at the mitotic apparatus: Implications for local translational control of cell division. Cell 103: 435-447.

Groisman, I., Jung, M.Y., Sarkissian, M., Cao, Q., and Richter, J.D. 2002. Translational control of the embryonic cell cycle. Cell 109: 473-483.

Hake, L.E. and Richter, J.D. 1994. CPEB is a specificity factor that mediates cytoplasmic polyadenilation during Xenopus oocytes maturation. Cell 79: 617-627.

Hake, L.E., Mendez, R., and Richter, J.D. 1998. Specificity of RNA binding by CPEB: Requirement for RNA recognition motifs and a novel zinc finger. Mol. Cell. Biol. 18: 685-693.

Jung, M.-Y., Lorenz, L., and Richter, J.D. 2006. Translational control by neuroguidin, an eIF4E and CPEB binding protein. Mol. Cell. Biol. 26: 4277-4287.

Kahvejian, A., Svitkin, Y.V., Sukarieh, R., M'Bboutchou, M.N., and Sonenberg, N. 2005. Mammalian poly(A)-binding protein is a eukaryotic translation initiation factor, which acts via multiple mechanisms. Genes \& Dev. 19: 104-113.

Karn, J., Watson, J.V., Lowe, A.D., Green, S.M., and Vedeckis, W. 1989. Regulation of cell cycle duration by c-myc levels. Oncogene 4: 773-787.

Kwak, J.E., Wang, L., Ballantyne, S., Kimble, J., and Wickens, M. 2004. Mammalian GLD-2 homologs are poly(A) polymerases. Proc. Natl. Acad. Sci. 101: 4407-4412.

Lutz, W., Leon, J., and Eilers, M. 2002. Contributions of Myc to tumorigenesis. Biochim. Biophys. Acta 1602: 61-71.

Malumbres, M. and Barbacid, M. 2005. Mammalian cyclin-dependent kinases. Trends Biochem. Sci. 30: 630-641.

Mateyak, M.K., Obaya, A.J., and Sedivy, J.M. 1999. c-Myc regulates cyclin D-Cdk4 and -Cdk6 activity but affects cell cycle progression at multiple independent points. Mol. Cell. Biol. 19: $4672-4683$.

Mendez, R., Hake, L.E., Littlepage, L., Ruderman, J.V., and Richter, J.D. 2000. Phosphorylation of CPE binding factor by Eg2 regulates translation of c-mos mRNA. Nature 404: 302-307.

Mendez, R., Barnard, D., and Richter, J.D. 2002. Differential mRNA translation and meiotic progression require Cdc2mediated CPEB destruction. EMBO J. 21: 1833-1844.

Michaloglou, C., Vredeveld, L.C., Soengas, M.S., Denoyelle, C., Kuilman, T., van der Horst, C.M., Majoor, D.M., Shay, J.W., Mooi, W.J., and Peeper, D.S. 2005. BRAFE600-associated senescence-like cell cycle arrest of human naevi. Nature 436: 720-724.

Minshall, N., Thom, G., and Standart, N. 2001. A conserved role of a DEAD box helicase in mRNA masking. RNA 7: 17281742 .

Morgenstern, J.P. and Land, H. 1990. Advanced mammalian gene transfer: High titre retroviral vectors with multiple drug selection markers and a complementary helper-free packaging cell line. Nucleic Acids Res. 18: 3587-3596.

Nakatani, Y. and Ogryzko, O. 2003. Immunoaffinity purification of mammalian protein complexes. Methods Enzymol. 370: 430-444.

Patil, C.K., Mian, S., and Campisi, J. 2005. The thorny path linking cellular senescence to organismal aging. Mech. Ageing Dev. 126: 1040-1045.

Pear, W.S., Nolan, G.P., Scott, M.L., and Baltimore, D. 1993. Immunoaffinity purification of mammalian protein complexes. Proc. Natl. Acad. Sci. 90: 8392-8396.

Pepper, D.S., Dannenberg, J.H., Douma, S., te Riele, H., and Bernards, R. 2001. Escape from premature senescence is not 
sufficient for oncogenic transformation by Ras. Nat. Cell Biol. 3: 198-203.

Richter, J.D. and Sonenberg, N. 2005. Regulation of cap-dependent translation by eIF4E inhibitory proteins. Nature 433: 477-480.

Ruan, H., Brawn, C.Y., and Morris, D.R. 1997. Analysis of ribosome loading onto mRNA species: Implications for translational control. In mRNA formation and function (ed. J.D. Richter), pp. 305-321. Academic Press, New York.

Ruggero, R., Montanaro, L., Ma, L., Xu, W., Londei, P., CordonCardo, C., and Pandolfi, P.P. 2004. The translation factor eIF-4E promotes tumor formation and cooperates with $\mathrm{c}$ Myc in lymphomagenesis. Nat. Med. 10: 484-486.

Sage, J., Mulligan, G.J., Attardi, L.D., Miller, A., Chen, S., Willians, B., Theodorou, E., and Jacks, T. 2000. Targeted disruption of the three Rb-related genes leads to loss of $\mathrm{G}(1)$ control and immortalization. Genes \& Dev. 14: 3037-3050.

Serrano, M., Lin, A.W., McCurrach, M.E., Beach, D., and Lowe, S.W. 1997. Oncogenioc ras provokes premature cell senescence associated with accumulation of p53 and p16INK4A. Cell 88: 593-602.

Sharpless, N.E., Bardeesy, N., Lee, K.H., Carrasco, D., Castrillon, D.H., Aguirre, A.J., Wu, E.A., Horner, J.W., and DePinho, R.A. 2001. Loss of p16Ink4a with retention of p19Arf predisposes mice to tumorigenesis. Nature 413: 86-91.

Sherr, C.J. 2004. Principles of tumor suppression. Cell 116: 235246.

Sherr, C.J. and Roberts, J.M. 2004. Living with or without cyclins and cyclin-dependent kinases. Genes \& Dev. 18: 26992711.

Sheth, U. and Parker, R. 2003. Decapping and decay of messenger RNA occur in cytoplasmic processing bodies. Science 300: $805-808$.

Stebbins-Boaz, B., Cao, Q., deMoor, C.H., Mendez, J., and Richter, J.D. 1999. Maskin is a CPEB-associated factor that transiently interacts with elF-4E. Mol. Cell 4: 1017-1027.

Stoneley, M., Paulin, F.E., Le Quesne, J.P., Chappell, S.A., and Willis, A.E. 1998. C-Myc 5' untranslated region contains an internal ribosome entry segment. Oncogene 16: 423-428.

Stoneley, M., Subkhankulova, T., Le Quesne, J.P., Coldwell, M.J., Jopling, C.L., Belsham, G.J., and Willis, A.E. 2000. Analysis of the c-myc IRES; a potential role for cell-type specific trans-acting factors and the nuclear compartment Nucleic Acids Res. 28: 687-694.

Tay, J. and Richter, J.D. 2001. Germ cell differentiation and synaptonemal complex formation are disrupted in CPEB knockout mice. Dev. Cell 1: 201-213.

Tay, J., Hodgman, R., Sarkissian, M., and Richter, J.D. 2003. Regulated CPEB phosphorylation during meiotic progression suggests a mechanism for temporal control of maternal mRNA translation. Genes \& Dev. 17: 1457-1462.

Thompson, E.B. 1998. The many roles of c-myc in apoptosis. Annu. Rev. Physiol. 60: 575-600.

Wilczynska, A., Aigueperse, C., Kress, M., Dautry, F., and Weil, D. 2005. The translational regulator CPEB1 provides a link between dcp1 bodies and stress granules. J. Cell Sci. 118: 981-992.

Wu, L., Wells, D., Tay, J., Mendis, D., Abbott, M.A., Barnitt, A., Quinlan, E., Heynen, A., Fallon, J.R., and Richter, J.D. 1998. CPEB-mediated cytoplasmic polyadenylation and the regulation of experience-dependent translation of $\alpha$-CaMKII mRNA at synapses. Neuron 21: 1129-1139. 


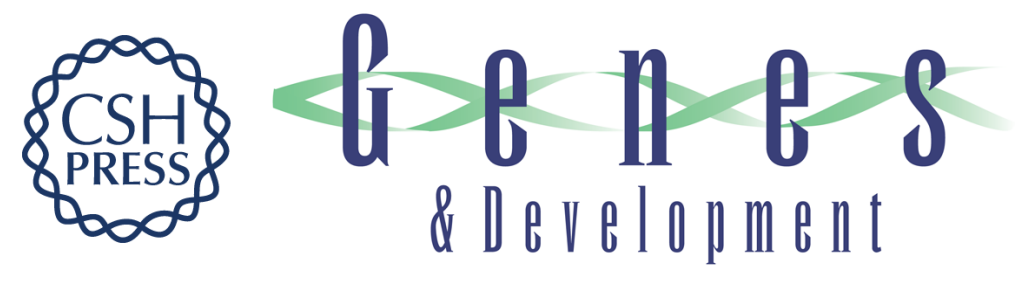

\section{Control of cellular senescence by CPEB}

Irina Groisman, Maria Ivshina, Veronica Marin, et al.

Genes Dev. 2006, 20:

Access the most recent version at doi:10.1101/gad.1438906

\section{Supplemental http://genesdev.cshlp.org/content/suppl/2006/09/19/20.19.2701.DC1 \\ Material}

References This article cites 52 articles, 20 of which can be accessed free at: http://genesdev.cshlp.org/content/20/19/2701.full.html\#ref-list-1

\section{License}

Email Alerting Receive free email alerts when new articles cite this article - sign up in the box at the top Service right corner of the article or click here.

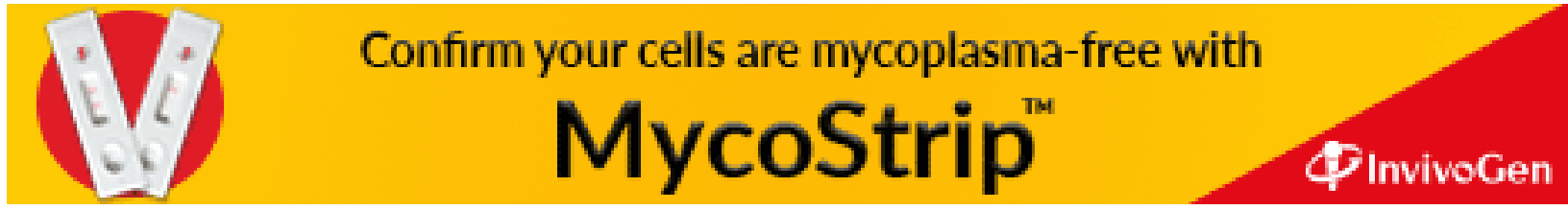

